\title{
LA MIGRACIÓN DE RETORNO: LOS JORNALEROS TAMAULIPECOS
}

SIMÓN PEDRO IZCARA PALACIOS

\section{Resumen}

La nueva economía de la migración laboral explica el retorno como resultado de un incremento de la privación y un decremento de la satisfacción en la sociedad receptora; es decir, un inmigrante retornará a su país de origen si se dan dos situaciones: que en la nueva sociedad otros tengan más bienes que él y/o que allí él tenga acceso a menos bienes que antes. Con este análisis se propone un equilibrio respecto del planteamiento propuesto por la economía neoclásica, que considera la migración como un proceso unidireccional, de manera que el retorno simboliza su fracaso. En este artículo se argumenta que los trabajadores rurales tamaulipecos empleados en la agricultura estadounidense retornan a sus comunidades porque su posición dentro de la jerarquía social en el país vecino es más baja que en su lugar de origen y, además, porque allí tienen acceso a menos bienes debido a que en Estados Unidos los costos de estos son más elevados que en Tamaulipas.

Palabras clave: migración de retorno, jornaleros, nueva economía de la migración laboral, Tamaulipas, Estados Unidos. 


\begin{abstract}
According to the new economy of labour migration, return migration is a result of increased privation and decreased satisfaction in the receiving society. In other words, an immigrant will return to his country of origin in two situations: when in the new society others have more goods than he and/or when he has fewer goods than before. This analysis offers a counterbalance to the approach proposed by neoclassical economics, which considers migration as a unidirectional process, whereby return symbolizes failure. This article argues that rural workers from Tamaulipas employed in U.S. farming return to their communities because in the host country their position within the social hierarchy is lower than in their place of origin, and because in the United States they have less access to goods since these are more expensive there.
\end{abstract}

Keywords: return migration, farm workers, new economics of labour migration, Tamaulipas, United States. 


\section{INTRODUCCIÓN}

$\mathrm{H}$ asta mediados de los años ochenta, el retorno constituía un hecho generalizado dentro del sistema migratorio México-Estados Unidos. La principal motivación para emigrar no era el deseo de establecerse de forma permanente en el país vecino (Massey et al., 2009:59). Sin embargo, la ley de amnistía de 1986 y el reforzamiento del control de la frontera alteró el funcionamiento de este sistema e interrumpió la frecuencia del retorno, de modo que durante los años noventa se produjo una disminución importante de la tasa de retorno (González González, 2009:60). En la medida en que se elevó el costo para emigrar a Estados Unidos, el retorno se tornó más contraproducente.

En el caso de Tamaulipas, la población rural ha emigrado durante décadas hasta el país vecino para emplearse como jornaleros e incrementar las escasas rentas generadas por el campo. Esta emigración se ha producido tanto de modo subrepticio como a través de programas de trabajadores huéspedes. Hasta los años ochenta, los jornaleros tamaulipecos cruzaban la frontera sin muchas dificultades, se establecían principalmente en el valle de Texas y su estancia allí duraba solamente unos meses. La política de contención de la emigración irregular centrada del lado de la oferta alteró la forma como los braceros tamaulipecos emigraron a Estados Unidos. A partir de los años noventa, los jornaleros tamaulipecos tuvieron que desplazarse a zonas más alejadas de la frontera en busca de mayores salarios, y dejó de ser rentable regresar después de una estancia corta en el país del norte. Desde 2004, pero principalmente desde febrero de 2010, la participación creciente de los grupos delictivos en la gestión del cruce fronterizo hizo la emigración al norte más cara y riesgosa. Ahora, el número de jornaleros tamaulipecos que emigran sin papeles es menor que cinco años atrás y la frecuencia del retorno se ha reducido. Como consecuencia, los programas de trabajadores huéspedes se han vuelto más atractivos, y cada vez es mayor el número de jornaleros que busca emigrar a través de las visas $\mathrm{H}-2 \mathrm{~A}$.

Durand (2004: 105) distingue tres tipos de retorno: la migración temporal sujeta a los programas de trabajadores huéspedes, el retorno del migrante que regresa después de una larga estancia, y el retorno 
transgeneracional. En este artículo parto del ejemplo de los trabajadores tamaulipecos empleados en el sector agrario estadounidense para estudiar los dos primeros tipos de retorno. En este trabajo se analiza por qué los jornaleros retornan a Tamaulipas.

Esta investigación está cimentada en una metodología cualitativa. La técnica utilizada para recabar el material discursivo fue la entrevista en profundidad. Se utilizó el muestreo estratificado intencional para seleccionar a los entrevistados, de modo que la muestra fue segmentada en dos estratos: i. jornaleros con experiencia de haber emigrado una o más veces a los Estados Unidos sin documentos, y ii. trabajadores que fueron contratados con visas H-2A para trabajar en la agricultura.

La muestra estuvo compuesta por un centenar de entrevistados. Entre marzo de 2007 y junio de 2008, en 38 comunidades rurales de trece municipios tamaulipecos, fueron entrevistados 50 jornaleros que emigraron sin documentos a los Estados Unidos para emplearse en la agricultura. La mitad de la entrevistas fue realizada en la zona más marginal de Tamaulipas, en el suroeste (en los municipios de Tula y Jaumave), donde la escasa rentabilidad del maíz, frijol y sábila obliga a los campesinos a emigrar. En la zona citrícola del centro del estado (en los municipios de Güémez, Hidalgo y Victoria), y en el área cañera del sur (en los municipios de El Mante y Antiguo Morelos), caracterizadas por una fuerte presencia de jornaleros, fueron realizadas trece entrevistas. En la zona este del estado (en los municipios de Aldama y Soto la Marina), una zona ganadera, fueron realizadas seis entrevistas. En el centro-noroeste (en los municipios de Villagrán y San Carlos), un área donde los bajos precios del maíz, frijol, cártamo y sorgo han favorecido un proceso de despoblación, fueron realizadas cuatro entrevistas. Finalmente, en el norte del estado (en el municipio de Valle Hermoso) fueron realizadas dos entrevistas.

Por otro lado, entre marzo de 2007 y octubre de 2008, fueron entrevistados 50 trabajadores rurales tamaulipecos que participaron una o más veces en el programa $\mathrm{H}-2 \mathrm{~A}$ de trabajadores huéspedes. Las entrevistas fueron realizadas en 30 comunidades rurales de nueve municipios: en la zona citrícola (compuesta por los municipios de Guémez, Hidalgo, Padilla, Llera y Victoria), se realizaron 35 entrevistas. En el suroeste (en los municipios de Jaumave y Tula), fueron seleccionados seis jornaleros. 
Finalmente, fueron seleccionados otros dos municipios rurales, uno del centro-noreste (Abasolo) y otro del centro-noroeste (San Carlos), caracterizados por una fuerte pérdida poblacional debida a la emigración ocasionada por la caída de rentabilidad del maíz, frijol, cártamo y sorgo. En el primero se realizaron seis entrevistas y tres en el último.

La selección de un número elevado de locaciones representativas de la diversidad del agro tamaulipeco tuvo como finalidad generar explicaciones de amplia resonancia (Mason, 1997:6; McCracken, 1988).

\section{SOBRE LA MIGRACIÓN DE RETORNO}

La reflexión en torno a la migración internacional no ha prestado una atención suficiente al estudio del retorno. La teoría económica neoclásica, la nueva economía de la migración laboral y la teoría del capital social ofrecen explicaciones de la migración de retorno contrapuestas y contradictorias.

La teoría económica neoclásica explica la migración a partir de un cálculo de costos y beneficios: los procesos migratorios son resultado de decisiones individuales guiadas por una racionalidad económica que busca una maximización del ingreso esperado a través del desplazamiento desde áreas caracterizadas por salarios bajos hacia zonas con salarios más elevados (Harris y Todaro, 1970:127; Herrera Lima, 2005:55 y 56).

Esta teoría contempla la migración como un proceso unidireccional que supone un abandono definitivo del lugar de origen. Debido a que el emigrante persigue una maximización de ingresos en la sociedad de acogida, donde encuentra mejores oportunidades económicas, el retorno es una expresión irrefutable del fracaso del proceso migratorio. El emigrante retorna a su comunidad de origen sólo si en la sociedad de destino no pudo sacar partido de las ventajas ofrecidas por un mercado laboral más favorable; por lo tanto, no existe posibilidad de un retorno exitoso. El migrante que retorna lo hace en una situación de penuria económica, porque en la sociedad de acogida no fue capaz de obtener más recursos que en la comunidad de origen. Regresar es dar marcha atrás, significa volver a la misma situación en que se encontraba al principio. 
Como contraste, la nueva economía de la migración laboral subraya el carácter transitorio de los procesos migratorios. El objetivo de la emigración es ahorrar lo suficiente para retornar y disfrutar de un mayor prestigio y estatus social en la comunidad de origen (Constant y Massey, 2002: 9-12).

El emigrante vive a caballo entre la sociedad de origen y la de acogida, donde experimenta diferentes niveles de "privación" y "satisfacción". El concepto de privación es relativo, porque mide la capacidad de un individuo de adquirir bienes en relación con el estándar de su grupo de referencia. Este término aparece definido por la ausencia. La privación es no tener aquello que es común dentro del grupo de referencia. El concepto de satisfacción mide la capacidad de un individuo para adquirir bienes y servicios. En el país de destino, el inmigrante experimenta más o menos satisfacción que en el de origen si su poder adquisitivo allí le permite adquirir más o menos bienes y servicios que en el lugar de partida. Asimismo, en la sociedad de acogida, el inmigrante sufre más o menos privación que en la de partida si su capacidad de adquirir bienes se encuentra más o menos alejada que en su comunidad del estándar prevalente en su nuevo grupo de referencia.

La satisfacción y la privación no son dos conceptos simétricos. Un inmigrante puede encontrar en el país de destino más satisfacción y menos privación que en el de partida; más satisfacción y más privación; menos satisfacción y menos privación, o menos satisfacción y más privación. Únicamente cuando en la sociedad receptora el inmigrante experimenta menos privación y más satisfacción que en el lugar de partida, los procesos migratorios se tornan unidireccionales (Izcara Palacios, 2009:13). Según Stark y Yitzhaki (1988:63), únicamente en el siguiente escenario no se produce el retorno:

$$
\left(\mathrm{P}_{\mathrm{B}}<\mathrm{P}_{\mathrm{A}}\right)+\left(\mathrm{S}_{\mathrm{B}}>\mathrm{S}_{\mathrm{A}}\right)
$$

Donde:

$\mathrm{P}=$ Privación

$\mathrm{S}=$ Satisfacción

A $=$ Sociedad de partida

$\mathrm{B}=$ Sociedad de destino 
Un ejemplo de este escenario aparece descrito por Thomas y Znaniecki (2004:255) cuando analizan la serie Raczkowski. En una carta escrita el 27 de Junio de 1906 por Adam Raczkowski desde Wilmington (Delaware) a su hermana Teófila, que residía en Polonia, al hablar de su hermano Franciszek Raczkowski señalaba: "en cuanto a nuestro país, el hermano dice que ya no va a regresar porque no hay nada allí que le haga regresar. No tiene propiedad allí y prefiere quedarse en Estados Unidos porque en nuestro país no podría ganar ni siquiera para una rebanada de pan". A continuación, al referirse a su situación decía: "y tampoco sé si yo voy a regresar. Si puedo regresar, quizás lo haga algún día, pero no me preocupa en absoluto no poder hacerlo, porque en Estados Unidos me va diez veces mejor de como me iría en nuestro país". Los hermanos Raczkowski no planean regresar a Polonia debido a que en Estados Uni$\operatorname{dos}\left(\mathrm{P}_{\mathrm{B}}<\mathrm{P}_{\mathrm{A}}\right)$ y $\left(\mathrm{S}_{\mathrm{B}}>\mathrm{S}_{\mathrm{A}}\right)$. Es decir, en Estados Unidos su privación era inferior a la que padecían en Polonia - como señalan Thomas y Znaniecki (2004:250), a través del progreso económico el campesino polaco podía elevar su posición social de forma más acelerada en Estados Unidos que en su lugar de origen - , y su satisfacción era mayor —como afirmaba Adam Raczkowski en la citada carta, en Estados Unidos le iba diez veces mejor que en su país-.

La nueva economía de la migración laboral contempla los escenarios de permanencia en la sociedad de acogida como una excepción. Mientras un único escenario " $\left(\mathrm{P}_{\mathrm{B}}<\mathrm{P}_{\mathrm{A}}\right)+\left(\mathrm{S}_{\mathrm{B}}>\mathrm{S}_{\mathrm{A}}\right)$ " implica el asentamiento en el país de acogida, hay tres escenarios - " $\left(\mathrm{P}_{B}>\mathrm{P}_{A}\right)+\left(\mathrm{S}_{B}<\mathrm{S}_{A}\right)$ "; " $\left(\mathrm{P}_{B}\right.$ $\left.<\mathrm{P}_{\mathrm{A}}\right)+\left(\mathrm{S}_{\mathrm{B}}<\mathrm{S}_{\mathrm{A}}\right)$ "; “ $\left(\mathrm{P}_{\mathrm{B}}>\mathrm{P}_{\mathrm{A}}\right)+\left(\mathrm{S}_{\mathrm{B}}>\mathrm{S}_{\mathrm{A}}\right)$ " - que favorecen el regreso a la comunidad de origen. Es decir, se produce el retorno cuando en el país receptor la privación es más elevada y la satisfacción más baja " $\left(\mathrm{P}_{B}>\mathrm{P}_{A}\right)$ $+\left(\mathrm{S}_{\mathrm{B}}<\mathrm{S}_{\mathrm{A}}\right)$ "; la primera y la última son más bajas " $\left(\mathrm{P}_{\mathrm{B}}<\mathrm{P}_{\mathrm{A}}\right)+\left(\mathrm{S}_{\mathrm{B}}<\mathrm{S}_{\mathrm{A}}\right)$ ", o las dos son más altas " $\left(\mathrm{P}_{B}>\mathrm{P}_{A}\right)+\left(\mathrm{S}_{B}>\mathrm{S}_{\mathrm{A}}\right)$ ".

A diferencia del modelo neoclásico que contempla el retorno como un fracaso, este modelo constituye, para la nueva economía de la migración laboral, una prueba del éxito del proyecto migratorio. Una persona emigra porque en su lugar de origen experimenta un nivel elevado de privación y bajo de satisfacción. El retorno significa que logró revertir esta situación debido a los ahorros acumulados en el país de 
inmigración. El migrante retorna siempre exitoso; nunca regresará de modo voluntario si a su llegada no puede acceder a más bienes y servicios de los que disfrutaba antes de emigrar, o si no puede escalar peldaños en la escala social, porque su capacidad de adquisición de bienes sigue estando por debajo del estándar de su grupo de referencia. Por lo tanto, la emigración se extenderá en el tiempo hasta que el migrante logre sobrepasar un umbral, que aparece definido por el nivel estándar de acceso a bienes y servicios de aquellos que constituyen su grupo de referencia en la comunidad de origen.

El capital social es la totalidad de los recursos actuales o potenciales asociados a la posesión de una red duradera de relaciones, o el conjunto de recursos basados en la pertenencia a un grupo (Bourdieu, 2001a:83; 2001b:148). Una forma de capital social son las redes migratorias (Deléchat, 2001:458, Arango, 2000:291) o vínculos sociales que ligan las comunidades emisoras con puntos de destino específicos y unen a migrantes y no migrantes dentro de una red compleja de roles sociales complementarios y relaciones interpersonales que son mantenidas por expectativas mutuas (Massey et al., 1987:139). Este capital social favorece el acceso a bienes económicos y empleo, y conduce a una disminución de los costos y los riesgos de la migración (García Caberra, 2004:468). Según Durand, "el capital social puede servir tanto para emprender una aventura migratoria como para regresar" (2004:110). Del mismo modo que la experiencia migratoria acumulada por una familia o comunidad dinamiza la emigración, el retorno exitoso de un miembro de una familia o comunidad motiva a otros inmigrantes a retornar. Como señala Durand, el inmigrante, al incrementar su capital social a lo largo del tiempo, y mantener y fortalecer sus vínculos con el lugar de origen, "cuenta con un sistema de apoyos que le facilitan el retorno y hacen menos riesgosa la aventura" (2004:112). Asimismo, el capital humano adquirido por el migrante en el país de acogida puede estimular el retorno, porque le facilita obtener mejores oportunidades económicas en el lugar de origen (Artola, 2009: 324).

Sin embargo, el capital social adquirido por el migrante no implica una mayor probabilidad de retorno, ya que tiene utilidad tanto en el país de emigración como en el de inmigración. A medida que las redes 
maduran, se genera una infraestructura social permanente que facilita el asentamiento en la sociedad de destino sin que se rompan los lazos con la comunidad de origen, ya que la circulación de gente e información entre los dos polos refuerza los lazos entre los mismos y permite a los migrantes echar raíces en los dos sitios (Massey et al., 1987:163). Durand (2004:115) afirma que el capital humano, social y monetario acumulado por el migrante después de haber trabajado largos años en el país de acogida puede ser utilizado tanto para quedarse como para regresar.

La tabla 1 representa de modo esquemático las diferencias en la explicación del retorno propuesta por las citadas teorías. Primeramente, la teoría económica neoclásica aparece enfocada en la permanencia de la migración; como contraste, la nueva economía de la migración laboral lo hace en el retorno, y la teoría del capital social presenta una posición intermedia. En segundo lugar, la primera teoría implica una ruptura de vínculos con el lugar de origen; como contraste, las otras dos subrayan el mantenimiento y/o fortalecimiento de los mismos. En tercer lugar, la capacidad de obtener ingresos más elevados en el lugar de destino incita a una persona a asumir el riesgo de la migración; sin embargo, la diferencia salarial tiene connotaciones diferentes para la explicación del retorno. La teoría económica neoclásica entiende las diferencias salariales como un elemento que anula la posibilidad del retorno: si los salarios son mucho más elevados en el lugar de destino, retornar carece de sentido en términos de una lógica de maximización de ingresos. Como contraste, la nueva economía de la migración laboral entiende las diferencias salariales como un mecanismo acelerador del retorno. Cuanto más elevada sea la diferencia de salarios entre los países de origen y destino, más pronto se producirá el retorno porque el migrante tardará menos tiempo en alcanzar el umbral de ingresos deseado. Para la teoría del capital social, los incrementos salariales pueden implicar un aumento o descenso de la probabilidad del retorno; en la etapa de formación de las redes migratorias, un ensanchamiento de las diferencias salariales puede adelantar el retorno; sin embargo, cuando estas maduran sucede lo contrario. Finalmente, la teoría económica neoclásica entiende el retorno como un fracaso del proyecto migratorio, la nueva economía de la migración laboral lo explica como 
el éxito del mismo, y en el marco de la teoría del capital social retornar no implica necesariamente éxito o fracaso. Un migrante exitoso puede retornar porque acumuló un umbral de ingresos o puede establecerse en la sociedad de acogida porque allí accede a mejores oportunidades económicas. Es decir, el capital social, humano y monetario acumulado por el migrante en el país de destino le permite tanto retornar como establecerse allí. Portes (2010:662) señala que los inmigrantes adultos de primera generación mantienen un contacto estrecho con el país de origen; como contraste, el transnacionalismo tiende a desaparecer en la segunda generación.

TABLA 1

Marcos explicativos de la migración de retorno

\begin{tabular}{|c|c|c|c|}
\hline & $\begin{array}{l}\text { Teoría } \\
\text { económica } \\
\text { neoclásica }\end{array}$ & $\begin{array}{l}\text { Nueva economía de la } \\
\text { migración laboral }\end{array}$ & $\begin{array}{c}\text { Teoría del capital } \\
\text { social }\end{array}$ \\
\hline $\begin{array}{l}\text { Meta del } \\
\text { emigrante }\end{array}$ & Definitiva & Temporal & Temporal $^{1} /$ Definitiva $^{2}$ \\
\hline $\begin{array}{l}\text { Vínculos con el } \\
\text { lugar de origen }\end{array}$ & Ruptura & Mantenimiento & Fortalecimiento \\
\hline $\begin{array}{l}\text { Diferencia } \\
\text { de salarios }\end{array}$ & $\begin{array}{l}\text { Disminuye la } \\
\text { probabilidad } \\
\text { del retorno }\end{array}$ & $\begin{array}{l}\text { Aumenta la } \\
\text { probabilidad } \\
\text { del retorno }\end{array}$ & $\begin{array}{c}\text { Incrementa o reduce } \\
\text { la probabilidad } \\
\text { del retorno }\end{array}$ \\
\hline Retorno & $\begin{array}{l}\text { Fracaso del } \\
\text { proyecto } \\
\text { migratorio }\end{array}$ & $\begin{array}{l}\text { Éxito del } \\
\text { proyecto } \\
\text { migratorio }\end{array}$ & $\begin{array}{l}\text { Éxito o fracaso del } \\
\text { proyecto migratorio }\end{array}$ \\
\hline
\end{tabular}

Fuente: elaboración propia.

\section{MIGRACIÓN INDOCUMENTADA Y RETORNO}

La emigración subrepticia de los trabajadores rurales tamaulipecos a Estados Unidos en busca de empleos agrarios se asienta en la experiencia de un elevado nivel de privación y en una situación de baja satisfacción. El sentimiento de privación surge porque las remesas conducen a un ascenso en la escala social de aquellas familias que las reciben, y a un 
descenso en las que carecen de ellas. La privación significa carecer de aquellos bienes y servicios que son accesibles a otros individuos o familias del mismo grupo de referencia (Izcara Palacios, 2009:19). Como decía Javier: "me dieron ganas de irme porque un conocido de aquí del ejido estaba allá; pues yo veía que su familia acá vivía muy bien. Tenían su buena casa, camioneta y bien vestidos, y pues cosa que la mía no tenía, y eso pues nos ponía tristes a mí y a mi señora”.

La situación de baja satisfacción emerge cuando las oportunidades económicas son tan escasas que un individuo o familia no pueden satisfacer las necesidades más básicas; señalaba Andrés:

En el ejido había poco trabajo en las parcelas porque la mayoría de las familias hacían su propio trabajo, así que los que buscábamos trabajo teníamos que ir hasta El Mante a buscarlo. Para ir al Mante había que levantarse bien temprano, como a las 3 de la mañana, ya que había que salir a la carretera a buscar un aventón, o había que aventársela caminando, pues había que estar a las 5 de la mañana en el puente, que es en donde se reúnen todos los trabajadores que buscan trabajo en el campo. Había días en que sólo hacíamos el viaje hasta El Mante y no encontrábamos trabajo, por lo que regresábamos a casa sin dinero. Era una situación muy difícil, a mí se me hacía muy feo y hasta me daban ganas de llorar; al acordarme de eso, más ganas me daban de irme al otro lado.

El retorno de los trabajadores indocumentados tamaulipecos obedece a que la posición de estos dentro de la jerarquía social en la sociedad de acogida siempre fue más baja que en la comunidad de origen. Los jornaleros de Tamaulipas experimentan un elevado grado de privación en el país vecino porque cuando comparan su poder adquisitivo con el de su nuevo grupo de referencia, se sitúa muy por debajo de la media. Es decir, en Estados Unidos, los otros (la población local y los otros jornaleros que se encuentran legalmente en el país) tienen más bienes que ellos.

Ser indocumentado implica percibir salarios más bajos, trabajar durante jornadas más largas y tener que rendir más en el trabajo que los jornaleros que tienen documentos. Los entrevistados remarcan que los trabajadores que tienen papeles reciben salarios más elevados que 
aquellos que no los tienen; las siguientes citas hacen referencia al trato discriminatorio que reciben los indocumentados: "Si va uno que trae papeles, le pagan a uno mejor la hora" (Eduardo). "La gente que va de ilegal agarra menos dinero que el que esta legal" (Jacinto). "A uno le pagan cualquier cosa, porque incluso yo me daba cuenta que la gente que tiene papeles allá cobran bien cara la hora" (Julia). "A esas personas que andaban con papeles, a ellos les pagaban más" (Graciano). "Si ocupan gente con papeles, tienen que pagarles más bien; entonces, si se les amontona el trabajo y pues quieren pagarles barato a la gente que les trabaje, pues por eso ocupan gente ilegal" (Daniela).

Esta situación genera un profundo enojo en algunos trabajadores que no tienen documentos: "Nosotros como ilegales sentíamos que trabajábamos más, pues los legales tenían derechos por tener contratos; pero, nosotros nada, y eso hacía que algunos compañeros se enojaran" (Ambrosio). "Sí había gente que les daba coraje no tener los papeles; porque así les podían pagar bien y no explotarlos” (Agustín). Sin embargo, la mayor parte de los indocumentados terminan por aceptar que no podrán gozar de las mismas condiciones laborales que disfrutan aquellos trabajadores que cuentan con un permiso de trabajo. Algunos autores (Linder, 1987:1335; Holley, 2001:579; Koreishi y Donohoe, 2010:68) han subrayado el estatus de segunda-clase de los jornaleros, aislados del resto de la clase trabajadora por políticas discriminatorias enraizadas en el New Deal; estas excluyeron a los asalariados agrarios del derecho de negociación colectiva, salarios mínimos y pago por horas extraordinarias. En el caso de los indocumentados, la situación es más precaria, porque estos quebraron la ley. Una vez que cruzan la frontera, no pueden dar marcha atrás, están obligados a trabajar en lo que sea, aunque el salario sea más bajo de lo esperado y las condiciones laborales más aciagas. Expresiones como "uno lo que le paguen está bien" (Daniela); "hay que trabajar en lo que salga" (Felipe) o "estando allá lo que te den es bueno" (Ángel) reflejan la falta de poder de negociación y actitud derrotista y conformista de los indocumentados.

Los empleadores corren un riesgo al dar empleo a alguien que no puede acreditar su estancia legal en el país; se exponen a ser sancionados. Este riesgo es contrarrestado con el pago de salarios más bajos y con 
mayores exigencias laborales; además, siempre hacen saber a aquellos trabajadores que no tienen papeles que no podrán pagarles tanto como a los que se encuentran legalmente en el país. Como señalaba Claudio: "ellos se arriesgan con nosotros al darnos trabajo, es por eso que más que nada ellos lo que hacen es pagarte la mitad". Algunos empleadores se rehúsan a pagar los salarios acordados, les descuentan horas trabajadas y otros pueden llegar al extremo de hacerles trabajar durante semanas sin ofrecerles ninguna remuneración. Cuando esto sucede, como decía Felipe, se encuentran indefensos: "a veces sí nos quedaban a deber, pero ya, cuando a uno ya no le pagan, ya qué hace, ya no puede hacer nada". Como no tienen documentos no pueden denunciar a su empleador, porque se arriesgarían a ser deportados; su única opción es aceptar una situación laboral muy desventajosa, o buscar empleo en otro sitio.

Por lo tanto, los jornaleros indocumentados tamaulipecos no ven reducida su privación en Estados Unidos, porque su posición social dentro de su nuevo grupo de referencia se encuentra más alejada del estándar prevalente allí que en su lugar de origen. Es decir, en Tamaulipas, el rango del migrante en la jerarquía social era más elevado que en Estados Unidos.

En Estados Unidos, los jornaleros indocumentados obtienen salarios más elevados que en Tamaulipas; pero esto no conduce a un incremento de su satisfacción, ya que el costo de la vida allí es mucho más elevado que en su comunidad de origen. Los salarios estadounidenses, más elevados, no les permiten incrementar su satisfacción, porque los bienes y servicios ofertados allí se elevan en la misma proporción que lo hacen sus ingresos. Casi todos los entrevistados repiten la idea de que el dinero que ganan en Estados Unidos no les rinde allí. Trabajar en Estados Unidos y vivir allí no les permite tener más bienes que trabajar y vivir en Tamaulipas. Los entrevistados suelen subrayar la idea de que un dólar en el país vecino les da acceso a los mismos bienes que un peso en su lugar de origen. Por lo tanto, un salario que en ocasiones puede multiplicar por diez los ingresos que recibirían por realizar una actividad similar en Tamaulipas, no les permite incrementar su satisfacción. En palabras de Eduardo: "allá es igual que aquí, pues allá es un dólar, pues es un peso de aquí, cinco dólar cinco pesos de aquí.” 
Los jornaleros tamaulipecos que cruzan sin papeles a Estados Unidos, lo hacen con un propósito concreto. Tan pronto como pueden satisfacer el propósito que se marcaron en un principio (construir una casa, comprar un carro, pagar una deuda o hacer frente a la educación de los hijos) su estancia en el país vecino carece de sentido. A partir de ese momento es cuando el migrante se plantea emprender el retorno: "A mí no me gusta Estados Unidos. Duré ese tiempo porque me fui con un propósito, y ya cuando lo hice me regresé" (Enrique). "Yo extrañaba a mis hijos y a mis papás. Por eso, mejor me vine, dije: «ya, como quiera, ya junté un poco de dinero, ya ayudé un poco a mis papás, ya me voy para México»" (Celestina).

\section{MIGRACIÓN TEMPORAL Y RETORNO}

Los visados temporales $\mathrm{H}-2 \mathrm{~A}$ constituyen un mecanismo de fomento de la inmigración ilegal (Durand, 2006: 67). La mayor parte de los jornaleros que reciben estas visas regresan a su lugar de origen cuando expiran. Sin embargo, hay trabajadores que ya no regresan. El hecho de que la mayor parte de los trabajadores huéspedes tamaulipecos entrevistados recordaban casos de personas que se quedaron en Estados Unidos después de terminar sus contratos es un elemento indicativo de que la exigencia contractual del retorno no siempre se cumple.

Cuando el Departamento de Seguridad Nacional de Estados Unidos autoriza una visa $\mathrm{H}-2 \mathrm{~A}$ busca que ese trabajador retorne. Para ello, realiza una rigurosa selección de los aspirantes. Se da preferencia a aquellos que participaron en el Programa en años anteriores y retornaron; como contraste, aquellas aplicaciones presentadas por trabajadores que no participaron anteriormente en el Programa pero, sobre todo, por aquellos que proceden de áreas urbanas o cuentan con un nivel de estudios elevado, es muy probable que sean rechazadas.

Un elemento que interfiere con el retorno son las redes sociales. Aquellos trabajadores que tienen familiares o amigos en Estados Unidos es menos probable que retornen después de concluir sus contratos. Decía Santiago: "había varios que no les parecía el trabajo o tenían familiares 
allá; pues se iban a otros lugares". Asimismo, Melchor señalaba: "yo me fui contratado a Virginia por tres meses y cumplí con el contrato; pero cuando lo terminé, es que como yo tenía un amigo en Florida y le llamé a mi amigo y me dijo cómo le hiciera, me fui con él a Florida para trabajar en la naranja".

La mayor parte de los entrevistados señalaron que quedarse en el país vecino después de expirar sus visas era algo contraproducente, ya que si no retornaban no podrían participar nuevamente en el Programa. Además, permanecer en Estados Unidos sin documentos les impediría acceder a salarios justos. Son muchos los entrevistados que, como Paulino, califican el no cumplir con la exigencia del retorno como "hacer mal las cosas": "muchos se van a otros lugares, pero pues eso está mal porque pues luego ya andaría uno de ilegal, entonces pues para qué se arriesga uno, mejor pues hacer bien las cosas".

Casi todos los entrevistados expresaron un elevado grado de satisfacción con el Programa $\mathrm{H}-2 \mathrm{~A}$, pero ninguno mostró intención de permanecer en el país vecino. Los trabajadores huéspedes tamaulipecos preferían trabajar de modo temporal en Estados Unidos que permanecer allí definitivamente. Se repiten frecuentemente en las entrevistas expresiones como: "para quedarse a vivir ahí, la verdad no" (Nicanor); "para vivir no me gustó, no me gustó por la comida" (Sergio); "uno lo que quiere es trabajar y ahorrar para mandar dinero para acá, ese es el objetivo, para vivir allá no" (Paulino). La dureza del trabajo y la dificultad de adaptarse a otra cultura, caracterizada por una distinta ética del trabajo y una gastronomía muy diferente de la tamaulipeca, hace que se sientan incómodos en Estados Unidos (Izcara Palacios, 2010: 270). Como señalaba Manuel: "uno está acostumbrado a nuestras costumbres, allá es otra vida".

El inmigrante aspira a quedarse de modo permanente sólo cuando encuentra en el país de destino una situación socioeconómica y laboral más satisfactoria que en su comunidad, y su posición social en la sociedad de acogida es superior a la que tenía anteriormente. Sin embargo, los jornaleros tamaulipecos que emigran con visados H-2A no incrementan su satisfacción en Estados Unidos. Además, experimentan un aumento de su privación relativa, porque disponen de 
menos recursos económicos que su grupo de referencia en la sociedad de acogida: viven en peores viviendas, su alimentación es más deficiente y su acceso al consumo es más limitado que el de la población local.

El programa de visas $\mathrm{H}-2 \mathrm{~A}$ permite a los jornaleros tamaulipecos trabajar en Estados Unidos durante unos meses y regresar a sus comunidades al concluir la temporada agrícola. Durante el tiempo que permanecen en el país vecino envían periódicamente sus ahorros a sus familias; generalmente, la esposa emplea una parte de las remesas en la reproducción familiar, pero otra porción es ahorrada para que el marido disponga de ella a su retorno. Esto hace que las familias de los jornaleros huéspedes empleados en el país vecino acrecienten significativamente la posición social dentro de sus comunidades. A diferencia de los indocumentados, que atraviesan rachas malas y buenas (en ocasiones están sobre-empleados, otras veces desempleados), los contratos firmados por los trabajadores huéspedes les garantizan ingresos constantes. Como consecuencia, es posible vislumbrar un antes y un después en las vidas de aquellos que participan en el Programa. El aspecto más visible son sus casas; estos agrandan sus viviendas o construyen casas que generalmente sobresalen entre las demás; sus hijos están mejor alimentados, visten mejor y pueden acceder a una mejor educación; casi todos se compran algún vehículo, y muchos tienen dinero ahorrado. Esto hace que aumente su satisfacción y que mengüe su privación cuando regresan a Tamaulipas.

Los ingresos que reciben en Estados Unidos no les permiten llevar una vida digna allí: sus salarios son bajos, viven en lugares apartados, trabajan hasta catorce horas diarias y casi nunca descansan. En Tamaulipas, su situación es muy diferente: tienen mucho tiempo de ocio y disponen de más recursos económicos que sus vecinos. Por lo tanto, los jornaleros tamaulipecos no desean permanecer en Estados Unidos; ir allí es un sacrificio. Las entrevistas reflejan sentimientos confrontados entre el deseo de trabajar en el país vecino: "Todos tenemos la ilusión de volver a trabajar allá" (Marcelino). "Uno está con la esperanza de que le hablen” (Rogelio) y el apego al terruño, reflejado en el discurso de Orencio, un jornalero de 40 años de edad, que aunque desde el año 2000 trabajaba en Arkansas por intervalos de nueve meses, todavía sentía 
temblores antes de partir hacia el norte: "Cuando ya falta un día para irme, ya que faltan horas, ya ando temblando de nervios, porque para mí aquí está muy bonito; verdad, yo quisiera andar aquí mejor".

Estados Unidos es descrito como el lugar donde trabajan y pueden ahorrar dinero rápidamente, pero ninguno de los entrevistados contemplaba el país vecino como un espacio donde podría rehacer su vida y residir de forma permanente. Los salarios más altos carecían de sentido allí, porque el costo más elevado de la vida mermaba su poder adquisitivo. La estrategia de los trabajadores huéspedes es reducir sus gastos en el país vecino, con el objeto de maximizar sus ahorros para incrementar su satisfacción y reducir su privación al momento de retornar. Como se refleja en las siguientes citas, el dinero ganado en el país vecino únicamente resulta rentable si se invierte en Tamaulipas: "Cuatrocientos dólar que gana uno a la semana allá, cuánto no es aquí, eso no lo saca aquí ni en un mes (...); el dinero acá es donde rinde, porque si se pone uno a gastar el dinero allá, pues no tiene caso" (Rogelio). "Si uno quiere comprar allá, pues no le queda nada, porque la única es que el dinero que uno gana allá, ahorrarlo, y ya cuando viene uno acá es donde se compra lo que quiere, porque acá es donde rinde el dinero que gana allá uno" (Ramiro). "Acá es donde rinde el dinero de allá, por eso pues allá uno no’ más deja para la comida y ya lo demás lo manda para acá" (Paulino). "Es mejor ahorrar el dinero y mandarlo para acá, y acá es donde rinde" (Santiago). "Aquí vale el dinero de allá, rinde más" (Rodolfo).

\section{CONCLUSIÓN}

Los trabajadores rurales tamaulipecos que emigran a Estados Unidos, tanto de forma indocumentada como con visas de trabajadores huéspedes, muestran una fuerte tendencia a retornar. El país vecino es contemplado como un espacio donde pueden ganar en meses lo que les llevaría años ahorrar en sus lugares de origen. Sin embargo, el mercado laboral estadounidense es más exigente que el tamaulipeco. Allí tienen que trabajar más horas, padecen una situación de aislamiento social y 
encerramiento en los campos agrícolas y, además, el dinero no les rinde porque el costo de los bienes y servicios es muy elevado.

Los jornaleros migratorios tamaulipecos no buscan una maximización del ingreso, sino que emigran con un propósito concreto, que queda satisfecho tras haber acumulado un umbral de ahorro predeterminado; tras haberlo sobrepasado, los que no tienen documentos retornan exitosos a su comunidad y aquellos que cruzaron la frontera en años anteriores con una visa $\mathrm{H}-2 \mathrm{~A}$ pierden la motivación para volver a hacerlo.

A finales del siglo XIX y comienzos del XX, los campesinos polacos que emigraban a Estados Unidos tendían a asentarse de modo permanente en el país receptor. Los hermanos Raczkowski no planeaban regresar a Polonia porque allí les iría mucho peor que en Estados Unidos. Los campesinos polacos podían elevar su posición social más rápidamente en América que en su lugar de origen. Como contraste, los campesinos tamaulipecos experimentan un descenso en su posición social en el país vecino. Aquellos que cruzan sin papeles descienden al último peldaño de la escala social porque se encuentran de modo ilegal en un país extraño, acceden únicamente a los empleos peor remunerados y están expuestos al arbitrio de sus empleadores. Los jornaleros que emigran con una visa temporal tampoco tienen los mismos derechos que los trabajadores autóctonos, son escogidos para realizar aquellas actividades que nadie quiere realizar, y sus salarios nunca superan el mínimo legal. Además, no logran elevar su satisfacción en el país de acogida, porque aunque obtienen más recursos económicos que en sus comunidades, estos ingresos superiores no se traducen en un mayor poder de compra.

Como señala la nueva economía de la migración laboral, el retorno de los jornaleros migratorios tamaulipecos se explica porque en Estados Unidos estos sufren una mayor privación que en Tamaulipas, ya que su posición dentro de la jerarquía social es más baja allá que aquí, y su satisfacción tampoco es más elevada. En un escenario donde " $\left(\mathrm{P}_{\mathrm{B}}>\mathrm{P}_{\mathrm{A}}\right)$ $+\left(\mathrm{S}_{\mathrm{B}}<\mathrm{S}_{\mathrm{A}}\right)$ " el retorno es la única opción factible. 


\section{REFERENCIAS}

Arango, J. (2000), "Explaining Migration: a critical view" en International Social Science Journal, 52 (165), pp. 283-296.

Artola, J. (2009), "La agenda internacional de las migraciones", en: HerreraLasso, L. (coordinador), México, país de migración, México, Siglo XXI, pp. 301-334.

Bourdieu, P. (2001a), "El capital social. Apuntes provisionales" en Zona Abierta, 94/95, pp. 83-87.

(2001b), Poder, derecho y clases sociales, segunda edición, Bilbao, Desclée de Brouwer.

Constant, A. y D. S. Massey (2002), "Return Migration by German Guestworkers: Neoclassical versus New Economic Theories" en International Migration, 40 (4), pp. 5-38.

Deléchat, C. (2001), "International Migration Dynamics: The Role of Experience and Social Networks" en Labour, 15 (3), pp. 457-486

Durand, J. (2004), "Ensayo teórico sobre la migración de retorno. El principio del rendimiento decreciente" en Cuadernos Geográficos 35 (2), pp. 103-116 (2006), Programas de trabajadores temporales. Evaluación y análisis del caso mexicano, México, Consejo Nacional de Población.

García Cabrera, S. V. (2004), "Migración, mujeres y estrategias de supervivencia en dos comunidades zacatecanas" en B. Suárez y E. Zapata Martelo (coords.), Remesas. Milagros y mucho más realizan las mujeres indígenas y campesinas, vol. II, México, GIMTRAP, pp. 463-494.

González González, E. (2009), "Características e implicaciones de la migración mexicana a Estados Unidos” en L. Herrera-Lasso (coord.), México, país de migración, México, Siglo XXI, pp. 19-72.

Harris, J. R. y M. P. Todaro (1970), “Migration, Unemployment and Development: A Two-Sector Analysis" en The American Economic Review, 60 (1), pp. 126-142.

Herrera Lima, F. F. (2005), Vidas itinerantes en un espacio laboral transnacional, México, Universidad Autónoma Metropolitana.

Holley, M. (2001), "Disadvantaged by Design: How the Law Inhibits Agricultural Guest Workers from Enforcing their Rights", Hofstra Labor \& Employment Law Journal, 18, pp. 573-621.

Izcara Palacios, S. P. (2009), "Privación relativa y emigración: El caso tamaulipeco", en Migraciones Internacionales, 5 (1), pp. 7-33. 
(2010), "Redes migratorias o privación relativa. La etiología de la emigración tamaulipeca a través del Programa H-2A” en Relaciones, 122, vol. XXXI, pp. 245-278.

Koreishi, S. y M. Donohoe (2010), "Historical and Contemporary Factors Contributing to the Plight of Migrant Farmworkers in the United Status" en Social Medicine, 5 (1), pp. 64-73.

Linder, M. (1987), "Farm Workers and the Fair Labor Standards Act: Racial Discrimination in the New Deal" en Texas Law Review, 65, pp. 1335-1387. Mason, J. (1997), Qualitative Researching, Londres, Sage.

Massey, D., J. Durand y N. J. Malone (2009), Detrás de la trama. Políticas migratorias entre México y Estados Unidos, México, Miguel Ángel Porrúa.

Massey, D., R. Alarcón, J. Durand H. y González (1987), Return to Aztlan. The Social Process of Internacional Migration from Western Mexico, Los Angeles, University of California Press.

McCracken, G. (1988), The long interview. Sage University Paper Series on Qualitative Research Methods, vol. 13. Beverly Hills, Sage.

Portes, A. (2010), "Un diálogo Norte-Sur: El progreso de la teoría en el estudio de la migración internacional y sus implicaciones”, en M. Ariza y A. Portes (coords.), El país transnacional. Migración mexicana y cambio social a través de la frontera, México, Miguel Ángel Porrúa, pp. 651-702.

STARK, O. y S. Yitzhaki (1988), "Labour migration as a response to relative deprivation" en Journal of Population Economics, 1, pp. 57-70.

Thomas, W. I. y F. Znaniecki (2004), El campesino polaco en Europa y en América, Madrid, BOE. 


\section{ANEXO: DATOS REFERENTES A LAS ENTREVISTAS CITADAS*}

\begin{tabular}{|c|c|}
\hline Agustín & $\begin{array}{l}\text { Entrevista realizada en noviembre de } 2007 \text { a un jornalero de } 23 \text { años } \\
\text { de edad de Barra del Tordo (Aldama) que emigró sin documentos a } \\
\text { Estados Unidos y trabajó en Georgia entre } 2002 \text { y } 2003 \text { en el melón y } \\
\text { la papaya. }\end{array}$ \\
\hline Ambrosio & $\begin{array}{l}\text { Entrevista realizada en noviembre de } 2007 \text { a un jornalero de } 60 \text { años de } \\
\text { edad de El Barranco (Aldama) que emigró sin documentos a Estados } \\
\text { Unidos y trabajó en Oklahoma y Atlanta entre los años } 1980 \text { al } 2005 \text { en } \\
\text { el tomate, el chile y el melón. }\end{array}$ \\
\hline Andrés & $\begin{array}{l}\text { Entrevista realizada en el mes de Diciembre de } 2007 \text { a un jornalero de } \\
43 \text { años de edad de La Loma (Antiguo Morelos) que emigró sin docu- } \\
\text { mentos a Estados Unidos y trabajó en Texas entre los años } 1978 \text { al } 1982 \\
\text { en el sorgo y la ganadería. }\end{array}$ \\
\hline Ángel & $\begin{array}{l}\text { Entrevista realizada en el mes de Diciembre de } 2007 \text { a un jornalero de } \\
38 \text { años de edad de México Libre (Antiguo Morelos) que emigró sin } \\
\text { documentos a Estados Unidos y trabajó en Texas entre los años } 1978 \text { al } \\
1982 \text { en la ganadería. }\end{array}$ \\
\hline Celestina & $\begin{array}{l}\text { Entrevista realizada en el mes de Diciembre de } 2007 \text { a una jornalera } \\
\text { de } 45 \text { años de edad de Palomas (Jaumave) que emigró sin documentos } \\
\text { a Estados Unidos y trabajó en Texas entre los años } 1990 \text { al } 1992 \text { en el } \\
\text { melón, la sandía y la cebolla. }\end{array}$ \\
\hline Claudio & $\begin{array}{l}\text { Entrevista realizada en el mes de Enero de } 2008 \text { a un jornalero de } 40 \\
\text { años de edad de La Reforma (Jaumave) que emigró sin documentos } \\
\text { a Estados Unidos y trabajó en Texas entre los años } 1990 \text { al } 1996 \text { en el } \\
\text { limón y la ganadería. }\end{array}$ \\
\hline Daniela & $\begin{array}{l}\text { Entrevista realizada en el mes de Junio de } 2008 \text { a una jornalera de } 37 \\
\text { años de edad de San Lorencito (Jaumave) que emigró sin documentos } \\
\text { a Estados Unidos y trabajó en Florida y Virginia entre los años } 1991 \text { y } \\
1992 \text { en el tomate y el chile. }\end{array}$ \\
\hline Donato & $\begin{array}{l}\text { Entrevista realizada en el mes de Octubre de } 2007 \text { a un jornalero de } 43 \\
\text { años de edad de Barranco Azul (San Carlos) que emigró sin documen- } \\
\text { tos a Estados Unidos y trabajó en Texas, Carolina del Norte, Virginia y } \\
\text { Florida entre los años } 1979 \text { al } 2007 \text { en la ganadería, el pepino, la manza- } \\
\text { na, el tomate, el tabaco y la naranja. }\end{array}$ \\
\hline Eduardo & $\begin{array}{l}\text { Entrevista realizada en el mes de Noviembre de } 2007 \text { a un jornalero de } \\
28 \text { años de edad de Barranco Azul (San Carlos) que emigró sin docu- } \\
\text { mentos a Estados Unidos y trabajo en Texas y Carolina del Norte entre } \\
\text { los años } 2003 \text { y } 2004 \text { en el tabaco y la sandía. }\end{array}$ \\
\hline Enrique & $\begin{array}{l}\text { Entrevista realizada en el mes de Abril de } 2008 \text { a un jornalero de } 32 \\
\text { años de edad de Soto la Marina que emigró sin documentos a Estados } \\
\text { Unidos y trabajó en Texas, Virginia y Florida entre los años } 2004 \text { al } \\
2007 \text { en la ganadería y el algodón. }\end{array}$ \\
\hline Felipe & $\begin{array}{l}\text { Entrevista realizada en el mes de Diciembre de } 2007 \text { a un jornalero de } \\
30 \text { años de edad de Tanque Blanco (Tula) que emigró sin documentos } \\
\text { a Estados Unidos y trabajó en Georgia entre los años } 1997 \text { al } 2007 \text { en } \\
\text { los pinos y el tomate. }\end{array}$ \\
\hline Graciano & $\begin{array}{l}\text { Entrevista realizada en el mes de Abril de } 2008 \text { a un jornalero de } 39 \\
\text { años de edad de Los Charcos (Tula) que emigró sin documentos a Es- } \\
\text { tados Unidos y trabajó en Texas en el año } 2005 \text { en la sandía y el melón. }\end{array}$ \\
\hline Jacinto & $\begin{array}{l}\text { Entrevista realizada en el mes de Octubre de } 2007 \text { a un jornalero de } 56 \\
\text { años de edad de R.F. Magón (Valle Hermoso) que emigró sin documen- } \\
\text { tos a Estados Unidos y trabajó en Luisiana y Tennessee entre los años } \\
1975 \text { y } 1980 \text { en el algodón. }\end{array}$ \\
\hline
\end{tabular}


Entrevista realizada en el mes de Enero de 2008 a un jornalero de 53

Javier años de edad de Victoria que emigró sin documentos a Estados Unidos y trabajó en Tennesee entre los años 1995 y 1997 en el tomate y el chile.

Entrevista realizada en el mes de Octubre de 2007 a una jornalera de

Julia $\quad 46$ años de edad de Guadalupe Victoria (Villagrán) que emigró sin documentos a Estados Unidos y trabajó en Texas, Florida, Nueva Jersey y Missouri entre los años 1986 y 2002 en la naranja, el pepino y la sandía.

Entrevista realizada en el mes de Noviembre de 2008 a un jornalero de

Manuel 34 años de edad de Guía del Porvenir (Abasolo) que emigró a Estados Unidos con una visa H-2A y trabajó en California en los años 2003 y 2004 en la manzana y las hortalizas.

Entrevista realizada en el mes de Noviembre de 2008 a un jornalero de

Marcelino 24 años de edad de Abasolo que emigró a Estados Unidos con una visa H-2A y trabajó en Illinois en el año 2004 en el maíz.

Entrevista realizada en el mes de Abril de 2007 a un jornalero de 32

Melchor años de edad de Santa Engracia (Hidalgo) que emigró a Estados Unidos con una visa H-2A y trabajó en Virginia en el año 2002 en la manzana

Entrevista realizada en el mes de Marzo de 2008 a un jornalero de 33 años de edad de Santa Engracia (Hidalgo) que emigró a Estados Unidos con una visa H-2A y trabajó en Texas entre los años 2003 y 2007 en el tomate y la naranja.

Entrevista realizada en el mes de Octubre de 2007 a un jornalero de 40

Orencio años de edad de Guadalupe Victoria (Hidalgo) que emigró a Estados Unidos con una visa H-2A y trabajó en Arkansas entre los años 2000 y 2007 en el pino.

Entrevista realizada en el mes de Octubre de 2008 a un jornalero de

35 años de edad de Guillermo Zúñiga (Hidalgo) que emigró a Estados
Unidos con una visa H-2A y trabajó en Carolina del Norte entre los

35 años de edad de Guillermo Zúñiga (Hidalgo) que emigró a Estados
Unidos con una visa H-2A y trabajó en Carolina del Norte entre los años 1999 y 2008 en el tabaco. Entrevista realizada en el mes de Enero de 2008 a un jornalero de 42

Ramiro años de edad de San Lorencito (Jaumave) que emigró a Estados Unidos con una visa H-2A y trabajó en Carolina del Norte entre los años 2001 y 2007 en el pino.

Entrevista realizada en el mes de Agosto de 2008 a un jornalero de 27

Rodolfo años de edad de La Unión Morales (San Carlos) que emigró a Estados Unidos con una visa H-2A y trabajó en Florida, Texas y Louisiana entre los años 2002 y 2008 en la naranja y la caña.

Entrevista realizada en el mes de Diciembre de 2007 a un jornalero de

Rogelio 46 años de edad de Tanque Blanco (Tula) que emigró a Estados Unidos con una visa H-2A y trabajó en Carolina del Norte entre los años 1995 y 2005 en el pino.

Entrevista realizada en el mes de Octubre de 2007 a un jornalero de 53

Santiago años de edad de Vicente Guerrero (Victoria) que emigró a Estados Unidos con una visa H-2A y trabajó en Carolina del Norte entre los años 1998 y 2006 en el tabaco.

Entrevista realizada en el mes de Abril de 2008 a un jornalero de 34

Sergio años de edad de Rancho Nuevo (Victoria) que emigró a Estados Unidos con una visa H-2A y trabajó en Arkansas en el año 2003 en el tomate.

Fuente: Elaboración propia.

${ }^{*}$ Los nombres son pseudónimos 